\title{
Avaliação heurística da usabilidade de um plug-in para o MOODLE
}

\author{
Giovanni Ferreira de Farias, \\ Rayse Kiane de Souza, \\ Francisco Antônio Pereira Fialho, \\ Fernando José Spanhol, \\ Márcio Vieira de Souza,
}

\section{INTRODUÇÃO}

Aprendizado baseado em problemas, mais conhecido como Aprendizagem Baseada em Problemas (ABP), é uma metodologia pedagógica muito utilizada especialmente na área médica desde os anos 60. Após o advento da Internet, diversas foram as iniciativas tecnológicas para viabilizar a implementação da metodologia em rede, seja em cursos a distância, seja em cursos presenciais com suporte de processos remotos. Dentre elas, o uso de plug-ins para adicionar funcionalidades ao ambiente virtual de aprendizagem MOODLE (MOODLE, 2016a), de modo a torná-lo apto a atender todos os detalhes procedurais da gestão de uma atividade ABP (FARIAS; SPANHOL; SOUZA, 2016a, 2016b).

Uma dessas tecnologias experimentais aditivas ao MOODLE foi avaliada para verificar a viabilidade de seu uso nos cursos ligados ao Programa de Pós-Graduação em Engenharia e Gestão do Conhecimento (PPGEGC) da Universidade Federal de Santa Catarina (UFSC). Para tanto, foi feita uma avaliação com as heurísticas de Nielsen para interfaces do usuário de software. O objetivo era validar a adequação do plug-in no que diz respeito à sua interface do usuário, para proporcionar facilidade e produtividade de uso, de modo a levar ao engajamento de professores do programa de pós-graduação à implantação da metodologia ABP suportada pelo MOODLE, equipado com o citado plug-in em seus respectivos cursos.

Este artigo descreve os procedimentos que foram tomados no processo de avaliação do plug-in com base nas heurísticas de Nielsen, fazendo uso de múltiplos avaliadores, que receberam instrução sobre a metodologia ABP e sobre o uso do plug-in para executar uma lista de tarefas pré-estabelecidas ${ }^{1}$.

1 Pelo fato de os desenvolvedores do plug-in não terem autorizado expressamente o uso 


\section{METODOLOGIA ABP}

Aprendizagem Baseada em Problemas, ou ABP, é uma metodologia de aprendizagem apresentada inicialmente por professores da Faculdade de Medicina da Universidade de McMaster, no Canadá, entre as décadas de 1960 e 1970, e seguidos pela Universidade de Maastricht, na Holanda. Foi proposta após a percepção da realidade clínica que os estudantes enfrentavam e frustrações nos resultados de aprendizado (CCDMD, s.d.). Diferente do ensino tradicional, com aulas expositivas, onde primeiramente os conceitos teóricos são passados aos alunos e posteriormente apresentado um exemplo prático, na metodologia ABP se começa apresentando aos alunos um problema prático para que seja solucionado por eles, de modo que estes venham a se deparar, nos seus estudos, com a busca da solução do problema, com conceitos necessários para o aprendizado. Por apresentar um caráter mais prático, o ABP que foi inicialmente difundido em faculdades de medicina, também passou a ser utilizado em outros cursos de graduação, como engenharias e arquitetura, por professores de ensino médio (BARROWS, 1996) e em processos de educação inclusiva (BELLAND; GLAZEWSKI; ERTMER, 2009).

A metodologia ABP se baseia em abordagens ativas ou colaborativas, onde o aluno é o protagonista no processo de aprendizagem, e dentro deste paradigma o professor assume o papel de suporte e orientador do processo (WOODS , 2000; WOOD, 2003; THOMAS, 2000; GOMES; REGO, 2011; WALKER; LEARY, 2009). As atividades desenvolvidas dentro do ABP são, em geral, realizadas por grupos que devem ser capazes de proporcionar aprendizagem significativa e por descoberta, valorização da autonomia do estudante e avaliação formativa (GOMES; REGO, 2011). Os tamanhos dos grupos podem variar de acordo com o autor, de cinco a nove estudantes para o modelo original de McMaster, porém, grupos maiores também podem alcançar resultados satisfatórios, como mostra Barrows (1996).

A implantação do ABP apresenta cinco passos básicos como descrito por Al-Dous e Samaka (2015), são eles:

1. Apresentação: os alunos são apresentados ao problema planejado pelo professor.

2. Identificação: a turma é dividida em grupos e os conhecimentos e competências necessárias para a solução do problema são identificadas.

da imagem do software no contexto da avaliação apresentada neste artigo, este texto não apresenta captura de telas do plug-in durante o processo de avaliação, tão pouco identifica o plug-in. O enfoque do texto, portanto, é a metodologia ABP e o processo de avaliação de interface de uma ferramenta usada para implementar o método, e não a ferramenta em si. 
3. Planejamento: será determinado o que será estudado, quem se encarregará de que, análise dos prazos, e que conceitos e competências serão estudos pelos integrantes do grupo.

4. Investigação ou Execução: cada grupo possui uma divisão de tarefas e cada componente realiza seus estudos (busca de informação, aquisição de conhecimento, desenvolvimento de artefato) que será compartilhado com os colegas.

5. Relatoria: apresentação dos resultados ou justificativa por não ter encontrado uma solução.

Esses passos de implementação, na realidade, são executados das mais diversas formas, dependendo da estratégia de planejamento do professor na implantação do curso ABP. Entretanto, podemos apresentar uma abordagem mais concreta de como eles são implementados através dos conceitos de fases e atividades distribuídos em uma lição ABP. A Figura 1 esquematiza o uso desses conceitos em uma lição ABP. Considerando o eixo do tempo, o processo começa com a concepção e montagem do plano e atividades da lição. Isso implica em pormenorizar as atividades que deverão ser realizadas pelos alunos, o levantamento do acervo de conteúdo que lhes será fornecido, bem como a especificação dos parâmetros de avaliação de aprendizado que serão utilizados para a lição.

\section{Lição ABP}

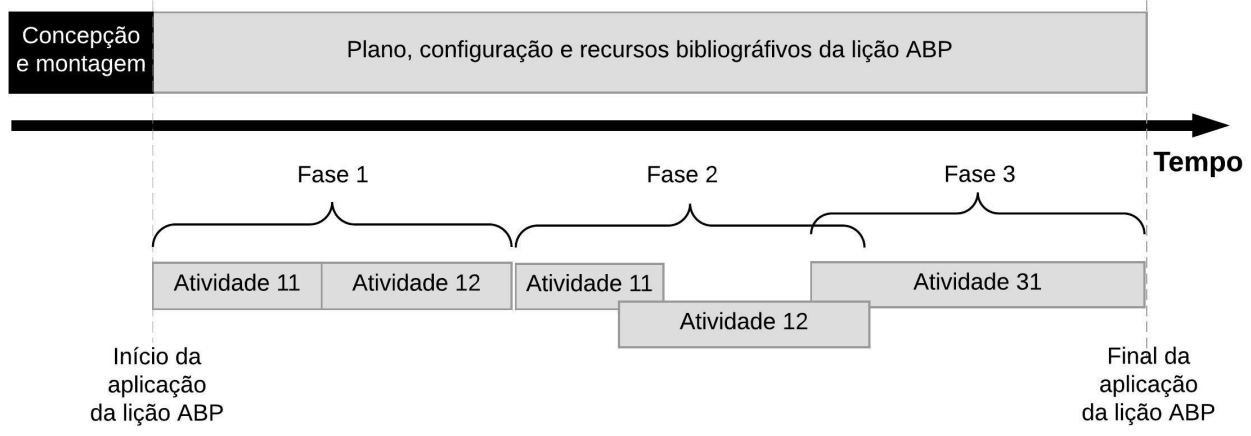

Figura 1: $\quad$ Exemplo de distribuição de fases e atividades sequenciais e concorrentes de uma lição $\mathrm{ABP}$ ao longo do tempo de sua implementação.

\subsection{FASES E ATIVIDADES DE UM CURSO ABP}

O resultado dessa etapa inicial é externado na preparação do MOODLE, fazendo o uso do plug-in para a publicação do plano de lição; em seguida, é feita a configuração inicial do plug-in, a qual envolve estabelecimento de cronograma com início e final de lição. Então, disponibilizam-se os arquivos, textos e links para conteúdo existente na Internet, para subsidiar os alunos com conceitos iniciais necessários à lição, bem como para explicitar os detalhes operacionais da 
metodologia ABP (WOODS, 1994).

O processo de aprendizagem pode ser dividido em fases, seguindo a lógica estabelecida pela metodologia ABP. Essas fases podem delinear os períodos voltados para diferentes tipos de atividades, por exemplo, entendimento da lacuna de conhecimento a ser preenchida com a busca da solução do problema, busca e compartilhamento de conhecimento obtido por pesquisa e/ou estudo, redação de documento com relatório sobre as atividades realizadas e avaliação dos resultados de aprendizagem. Ou seja, cada fase estabelecida pode ter uma ou mais atividades, cada uma delas voltadas para uma ação específica prevista na metodologia ABP (WOODS, 1994).

As fases podem ocorrer de forma sequencial e/ou paralela, sendo permitida a interseção de fases ao longo da lição, como é ilustrada na Figura 1 pela interseção das fases 2 e 3. Pode ser observado na mesma figura que o mesmo ocorre com as atividades, que também podem ser alocadas cronologicamente de forma sequencial e/ou paralela, com interseção cronológica entre elas. O entendimento que se deve ter da Figura 1 é sobre a importância do estabelecimento de um cronograma de fases e atividades ao longo do período de implementação de uma lição ABP no modelo ABP de Woods (1994).

\subsection{CONHECIMENTOS EM CONCEITOS E COMPET NCIAS EM PROCESSOS}

A metodologia ABP preconiza a avaliação de dois aspectos do processo de aprendizagem, a aquisição de conhecimento em conceitos e a aquisição de competências em processos (WOODS, 2006). Os conhecimentos em conceitos adquiridos por um aluno ao longo de qualquer curso correspondem ao aprendizado sobre a teoria na qual o curso foca, o que tradicionalmente é feito em qualquer método expositivo de aprendizagem. Já as competências em processos dificilmente são incluídas numa abordagem expositiva de ensino, pois envolvem as habilidades individuais e sociais do aluno durante o processo de aprendizagem, tais como: trabalhar em grupo, desenvolver autonomia, apresentar proatividade, promover sua socialização entre os seus pares, realizar comunicação eficiente e eficaz de ideias, além de evoluir nas capacidades de análise, julgamento, reflexão e tomada de decisão (GOMES; REGO, 2011; WOODS, 2006; WALKER; LEARY, 2009).

Woods (2006) ainda defende dois pontos importantes na implementação de ABP em um curso. O primeiro ponto é a necessidade de explicitação da importância do desenvolvimento de competências em processos durante as atividades de um curso em ABP. O aluno tem de ser claramente comunicado sobre como ocorre o processo de aprendizagem baseado na metodologia ABP e sobre seus detalhes operacionais, incluindo informações sobre prazos a serem cumpridos, expectativas sobre a atitude do aluno, procedimentos a serem realizados e como ocorre a avaliação (especialmente sobre aquisição de competências em processos). 
O segundo ponto é sobre equalizar os pesos de avaliação sobre a aquisição de conhecimento de conceitos e sobre competências em processos, considerados ideais por Woods (2006), já que crê que tão importante para o aluno quanto aprender conceitos teóricos é desenvolver habilidades de aquisição de tais conceitos e interação social para aplicá-los.

\subsection{AVALIAÇÃO DA APRENDIZAGEM EM ABP}

Além de avaliar os conhecimentos em conceitos e as competências em processos, Woods (2006) orienta que, em uma lição ABP, o professor compartilhe com o próprio aluno e com seus colegas a responsabilidade de fazer a avaliação de seu aprendizado. O quadro 1 mostra os tipos de protagonista no processo de avaliação segundo Woods (2006), com as respectivas definições.

O professor acaba sendo mais importante nos processos de avaliação dos conhecimentos de conceitos adquiridos ao longo do curso, já que isso necessita de entendimento aprofundado sobre o que está sendo avaliado. Um artefato pode servir de subsídio para que o professor avalie a aprendizagem do aluno. Esse artefato pode ser um documento que demonstre o conhecimento teórico adquirido, como a entrega um trabalho de autoria individual ou do grupo, a apresentação de um seminário para a turma, ou qualquer outro recurso que subsidie o professor de informação necessária à avaliação do conhecimento conquistado ao longo do curso. Isso inclui avaliação formativa do aprendizado teórico, em que o professor se baseia na demonstração de aquisição dos conceitos pelo aluno através do comportamento, atitude, desenvoltura na abordagem do tema, entre outros fatores empíricos.

Muito embora, com a observação feita sobre o que ocorre em sala de aula ou nos encontros com o grupo, o professor também possa ter elementos que subsidiem a sua avaliação de cada aluno na aquisição de competências em processos, as atividades que levam a tal competência ocorrem majoritariamente fora do alcance do professor. Dessa forma, segundo Woods (2006), para que o professor possa avaliar plenamente as competências em processos, o aluno deve relatar os acontecimentos ao longo de todo o desenvolvimento da ABP, escrever reflexões a respeito do seu do aprendizado e suas atitudes individuais, fornecer suas percepções sobre si mesmo (autoavaliação) e sobre seus colegas de grupo (avaliação dos pares), explicitar o conhecimento tácito adquirido sobre conceitos em forma de texto. Dessa forma, o professor poderá avaliar tanto o conhecimento em conceitos quanto as competências em processo que estão sendo adquiridas ao longo da lição ABP (WOODS, 2006). 


\begin{tabular}{|l|l|}
\hline \multicolumn{1}{|c|}{ Protagonista } & \multicolumn{1}{c|}{ Definição } \\
\hline Professor & $\begin{array}{l}\text { Avaliação feita pelo professor sobre o } \\
\text { conhecimento de conceitos ou aquisição } \\
\text { de competências em processos. }\end{array}$ \\
\hline Autoavaliação & $\begin{array}{l}\text { Avaliação feita pelo próprio aluno, com } \\
\text { base em reflexão ou em uso de rubrica } \\
\text { fornecida pela lição ABP. }\end{array}$ \\
\hline Colegas de grupo & $\begin{array}{l}\text { Avaliação feita pelos colegas do grupo de } \\
\text { trabalho do qual o aluno participou da } \\
\text { atividade ABP. }\end{array}$ \\
\hline Colegas de turma & $\begin{array}{l}\text { Avaliação feita pelos colegas da turma, } \\
\text { envolvendo alunos dos outros grupos de } \\
\text { trabalho ABP. }\end{array}$ \\
\hline
\end{tabular}

Quadro 1: Tipos de protagonista de avaliação de atividades ABP.

Fontes: Autores (2018).

Note que o fornecimento de um relatório ou um texto reflexivo do aluno para o professor avaliá-lo, ou mesmo de respostas sobre o comportamento de um colega com base em um formulário, podem constituir um artefato a ser entregue para fins de avaliação de competências em processos, tal como outro artefato pode-se referir a um trabalho sobre os conceitos teóricos do curso. Portanto, a ideia de artefato não necessariamente está ligada apenas à avaliação de conhecimento em conceitos.

Todas as concepções sobre ABP que foram descritas aqui foram criadas para um cenário de educação presencial, pois são oriundas de uma época em que não existia Internet. Porém, nada impede que esses conceitos possam ser usados em um cenário de educação a distância ou educação híbrida, processo educacional que envolve tanto atividades presenciais quanto remotas, em geral via Internet. Por isso surgiu o conceito de ABP em rede, que é o ABP mediado por tecnologias de Internet, assunto tratado na próxima seção.

\subsection{ABP EM REDE}

Apesar de a Internet ter surgido comercialmente no início dos anos noventa, somente nos anos 2000 algumas ferramentas específicas para ABP começaram de ser desenvolvidas (FARIAS; SPANHOL; SOUZA, 2016a). Porém, esses sistemas especialistas em $\mathrm{ABP}$ se mostraram problemáticos devido às inúmeras variantes das metodologias, e muitas das soluções são desenvolvidas a um objetivo específico, não suportando a maioria dos modelos e cenários do ABP (ALI; SAMAKA; SHABAN, 2011). Partiu-se para o uso de tecnologias que habilitassem ambientes virtuais de aprendizagem (AVA) para atender as necessidades operacionais de $\mathrm{ABP}$ em rede, como detalhado na próxima seção. 


\section{ABP EM REDE SUPORTADO POR AVA COM PLUG-IN}

Com um alto consumo de recursos humanos e desenvolvimento das aplicações especialistas em ABP, uma outra abordagem para desenvolvimento de frameworks que suportassem ABP em rede surgiu no final dos anos 2000 (FARIAS; SPANHOL; SOUZA, 2016b). Tratou-se do desenvolvimento de plug-ins para AVAs de código aberto e já bem estabelecidos no mercado, como por exemplo o MOODLE - Modular Object Oriented Dynamic Learning Environment (MOODLE, 2016a; ALI; AL-DOUS; SAMAKA, 2015).

O que motiva essa escolha é simplesmente o fato de que se uma instituição já usa o MOODLE, o desenvolvimento de um plug-in apresenta custos bem menores do que no caso de um sistema especialista, haja visto que a evolução das funções do AVA é proporcionada pela comunidade de desenvolvedores que o suporta. O desenvolvedor do plug-in fica responsável apenas pela manutenção e aprimoramento do próprio plug-in, cujas funções se restringem às necessidades específicas da metodologia ABP em rede. Funções como as responsáveis pelos debates através de fóruns e chats, recebimento de artefatos, distribuição de arquivos para os alunos, entre outros, já estão prontas e são constantemente atualizadas nos AVAs.

Por outro lado, para Ali, Al-Dous e Samaka (2015) a utilização do AVA puro para aplicação de ABP pode gerar frustrações aos participantes do processo, pois apresenta limitações pedagógicas devido à falta de certas funcionalidades necessárias à aplicação da metodologia. Desse modo, o desenvolvimento de um plug-in serve para expandir as funcionalidades do AVA para suportar o paradigma ABP, acrescentando apenas os recursos inerentes ao processo de implementação da metodologia.

\subsection{A LÓGICA DE FUNCIONAMENTO DO PLUG-IN EPBL NO MOODLE}

Quando o plug-in ePBL é instalado no MOODLE, é classificado como um módulo, ou seja, passa a ter o mesmo status de outra atividade do MOODLE, como um fórum, chat, tarefa ou questionário. Uma vez criada uma instância do plug-in na grade de programa de um curso no MOODLE, o módulo do plug-in permite que o professor configure as funcionalidades inerentes à metodologia $\mathrm{ABP}$, como publicação de texto declaratório sobre o problema a ser solucionado, as regras de andamento do processo ABP, cronograma de fases e atividades, distribuição de avaliação pelos protagonistas e funcionalidades para operação do trabalho.

Essas funcionalidades de operação são divididas em três tipos: recursos, ferramentas e artefatos (ALI; SAMAKA; SHABAN, 2011). Para tanto, o plug-in usa 
funcionalidades do MOODLE, que por sua vez usa outra classificação para tais funcionalidades ${ }^{1}$, mas esse texto mantém a terminologia de Ali, Samaka e Shaban (2011).

\subsubsection{Recursos e atividades do MOODLE utilizados pelo plug-in}

Para explicar o funcionamento do plug-in sem a necessidade de ter conhecimento aprofundado no uso do MOODLE, o Quadro 2 apresenta as funcionalidades dos outros módulos do MOODLE que o módulo do plug-in faz uso para implementar as funções necessárias à operacionalização de uma lição ABP. Os ícones utilizados originalmente pelo MOODLE para tais funcionalidades também são apresentados para indicar que funcionalidade MOODLE é usada para cada operação pelo plug-in e também para facilitar o entendimento de como tais recursos são utilizadas pelo plug-in nas figuras que seguem no Quadro 2.

Os Recursos são funcionalidades do MOODLE ligadas à publicação de conteúdo, sem estar associadas a interatividade ou a avaliação. São elas: Arquivo, Página Web, Livro e URL, explicadas no Quadro 2.

As Ferramentas são funcionalidades do MOODLE voltadas para viabilizar interação entre os participantes de um curso online. São elas: Fórum, para comunicação assíncrona, e Chat, para comunicação síncrona.

Já o termo Artefato usado pelo plug-in relaciona dois tipos distintos de funcionalidades do MOODLE. Um é o módulo Tarefa, que permite que alunos entreguem trabalhos através do MOODLE, usando ou texto editado online com o editor HTML, ou envio de arquivo para a plataforma, para posterior avaliação do professor ${ }^{2}$. Trata-se, portanto, de uma funcionalidade eminentemente voltada para avaliação de trabalhos, feita apenas pelo professor.

O outro tipo de funcionalidade do MOODLE é o módulo Wiki, cujo enfoque é mais colaborativo, pois permite que seja feita edição compartilhada de do-

$1 \mathrm{Na}$ terminologia do MOODLE, o termo recurso implica as mesmas funcionalidades indicadas por Woods (2006). Porém, as funcionalidades referentes às ferramentas e aos artefatos, para Woods (2006), são classificadas na terminologia do MOODLE como sendo atividades para ambas.

2 O módulo Tarefa do MOODLE também permite a inserção de notas sem que haja entrega de texto online ou arquivo. É usado para avaliação de atividades que ocorrem presencialmente, sem qualquer relação com o ambiente virtual. Como o funcionamento do plug-in ignora essa variante do uso do módulo Tarefa, o texto não apresenta essa sua finalidade de uso. 
cumento editado online, através do editor de texto HTML do MOODLE, de forma bastante controlada, inclusive com histórico de apresentação e restrição de edição a um grupo pré-determinado. Trata-se, assim, de uma ferramenta eminentemente colaborativa, que originalmente não está associada diretamente a nenhuma função de avaliação no MOODLE.

\begin{tabular}{|c|c|c|c|}
\hline Categoria & Ícone & Nome & Funcionalidade no MOODLE \\
\hline \multirow[t]{4}{*}{ Recurso } & & Arquivo & $\begin{array}{l}\text { Publica arquivos no MOODLE } \\
\text { para download pelos alunos. }\end{array}$ \\
\hline & & Página Web & $\begin{array}{l}\text { Publica conteúdo em uma página } \\
\text { única, através do editor de texto } \\
\text { online do MOODLE. }\end{array}$ \\
\hline & & Livro & $\begin{array}{l}\text { Publica conjunto agrupado de } \\
\text { páginas web, com uso do editor } \\
\text { de texto online do MOODLE. }\end{array}$ \\
\hline & & URL & $\begin{array}{l}\text { Publica link para endereços } \\
\text { externo ao MOODLE na Internet. }\end{array}$ \\
\hline \multirow[t]{2}{*}{ Ferramenta } & & Fórum & $\begin{array}{l}\text { Disponibiliza fórum online para } \\
\text { promover discussão temática } \\
\text { entre alunos no MOODLE. }\end{array}$ \\
\hline & & Chat & $\begin{array}{l}\text { Disponibiliza chat para promover } \\
\text { conversa textual em tempo real } \\
\text { no MOODLE. }\end{array}$ \\
\hline \multirow[t]{2}{*}{ Artefato } & & Tarefa & $\begin{array}{l}\text { Disponibiliza mecanismo para } \\
\text { aluno enviar arquivos para o } \\
\text { MOODLE. }\end{array}$ \\
\hline & 돼ㄴㅛㅛㄹㅛ & Wiki & $\begin{array}{l}\text { Disponibiliza mecanismo de } \\
\text { construção colaborativa de } \\
\text { documentos online no MOODLE. }\end{array}$ \\
\hline
\end{tabular}

Quadro 2: Recursos e atividades do MOODLE utilizados pelo plug-in para implementar os processos ABP em rede.

Fonte: Autores (2018).

Desse modo, contextualizando o uso das funcionalidades do MOODLE dentro da lógica do funcionamento do plug-in, vemos na Figura 2 que fases são estabelecidas para a lição ABP; depois, são alocadas atividades dentro das fases. Por último ${ }^{3}$, as funcionalidades do MOODLE, chamadas de recursos, ferramen-

3 A sequência de criação da fase para depois criar uma atividade dentro da mesma é 
tas e artefatos na interface do usuário do plug-in ePBL são relacionados a uma ou mais atividades contida na fase, como mostra a Figura 2.

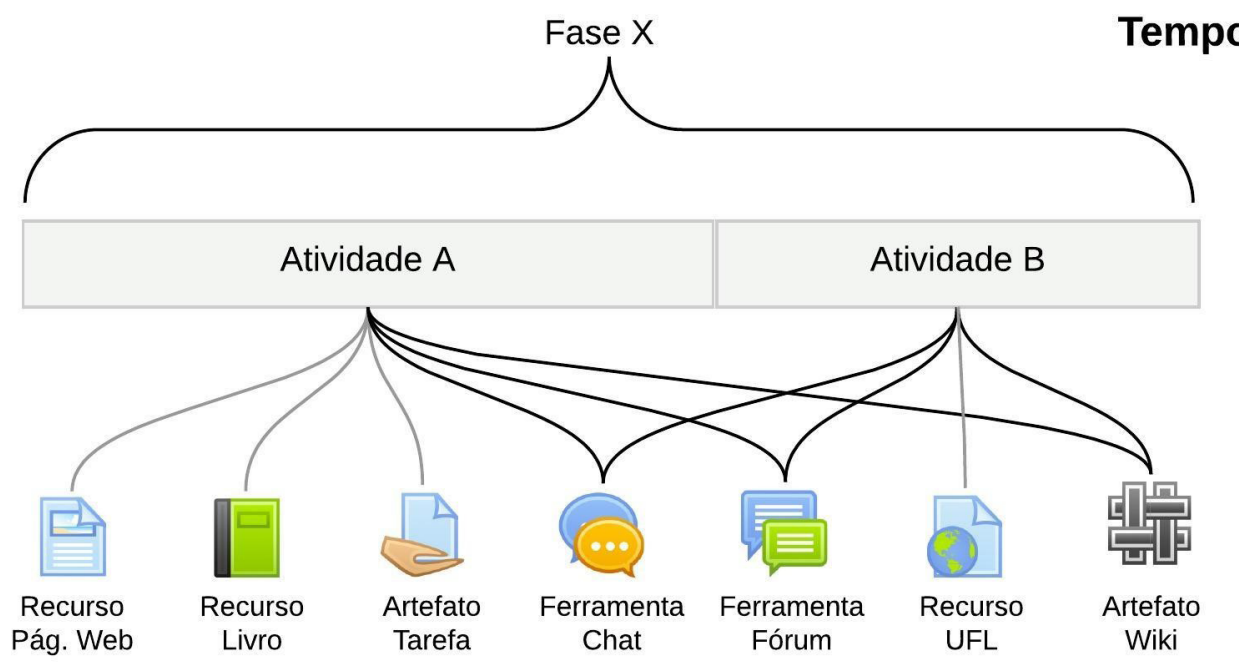

Figura 2: Recursos, ferramentas e artefatos relacionados com atividades de uma fase da lição ABP.

Fonte: Autores (2018)

Note que a forma com que o plug-in aloca os recursos, ferramentas e artefatos independe das atividades às quais eles estão associados. Em outras palavras, uma vez criadas as instâncias de páginas web, livros, links, fóruns, chats, wikis e tarefas, eles ficam associados à fase onde foram criados. O sequenciamento deles se dá pela sequência de atividades que foi configurada, associando cada item criado a uma ou mais atividades. Isso implica que, como no exemplo da Figura 3, os recursos Página Web e Livro, além do artefato Tarefa, estarão disponíveis para o aluno apenas durante o prazo da Atividade A. As ferramentas Chat e Fórum, apesar de estarem alocadas na Atividade A, também estão alocadas na Atividade B, o que garante que estejam disponíveis para o aluno durante toda a Fase X. O mesmo

obrigatória. Porém, depois de criada a fase, não necessariamente a sequência de montagem de uma lição ABP deve seguir da atividade para depois recursos, ferramentas e artefatos. Esses quatro elementos podem ser criados independentemente e serem vinculados uns aos outros posteriormente, através de funcionalidades presentes no plug-in. 
ocorre com o Artefato Wiki, que está alocado em ambas as atividades da Fase X. Já o recurso URL só fica disponível para os alunos quando a Atividade B iniciar, já que está alocado apenas nessa atividade.

Agora que foram apresentados os paradigmas de fase, atividade, recurso, ferramenta e artefato de uma lição ABP, bem como os protagonistas da avaliação da aprendizagem, vejamos como o plug-in integra todos esses conceitos na sua operação.

\subsubsection{Processo de estruturação de lição ABP com o plug-in}

Acompanhe a explicação dos procedimentos de como o plug-in avaliado neste estudo estrutura uma lição ABP. A Figura 3 ilustra as funcionalidades presentes na interface do plug-in que precisam ser configuradas, bem como os recursos que precisam ser instanciados no MOODLE para montagem da lição ABP.

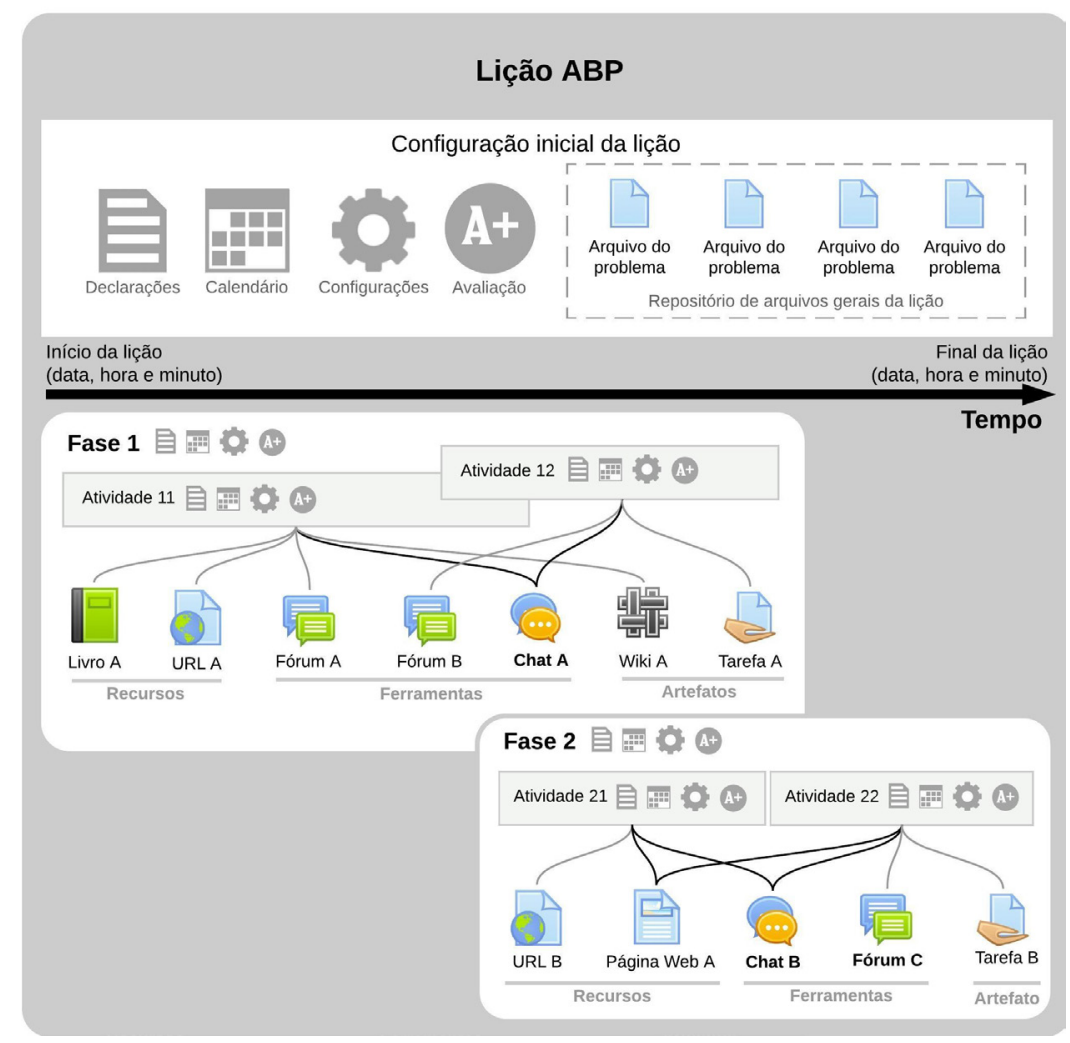

Figura 3: Esquema de estruturação de uma lição ABP segundo funcionalidades disponíveis no MOODLE.

Fonte: Adaptado Ali, Samaka e Shaban (2011). 
Note que a sequência de procedimentos a serem realizados começa com a configuração da lição, depois das fases da lição, e finalmente das atividades em cada fase, tal como ilustrado também na Figura 1. O eixo do tempo, que vai da esquerda para a direita, representa os momentos em que o aluno tem acesso à lição, às suas fases e às respectivas atividades.

\subsubsection{Configuração da lição ABP}

Assim que se cria uma instância do módulo do plug-in ePBL no MOODLE, a página de configuração inicial que surge permite que o professor faça as declarações pertinentes: título, descrição, recursos da lição ABP, inclusive publicando links ou incorporando vídeos elucidativos sobre o processo ABP da lição. Também se realiza a configuração de vários detalhes, como se haverá permissão ou não para que as fases da lição possam ocorrer concomitantemente, e configurações inerentes à operação do MOODLE. Porém, em termos de configurações, as mais importantes têm representação gráfica própria na Figura 3, que são as dos prazos para início e fim da lição ABP e a da nota total que será computada pela combinação das notas obtidas pelas diversas atividades da lição. Além disso, o professor tem na mesma página um mecanismo de envio de arquivos, que pode ser usado para fornecer aos alunos subsídios que os ajudem nas atividades da lição ABP, chamados na Figura 2 de "Arquivos do Problema".

Convém mencionar que as informações contidas nas declarações e os arquivos disponibilizados nessa fase inicial de configuração ficam disponíveis aos alunos durante todo o período de atividades da lição ABP. Por isso que o quadro referente à configuração da lição segue de um lado a outro da Figura 2, pois ocupa toda a faixa de tempo, do início ao final da lição. Feita e salva a configuração inicial da lição, o professor poderá começar a montagem das fases e atividades, o que é mostrado a seguir.

\subsubsection{Configuração da fase da lição $A B P$}

O processo de configuração de uma fase se assemelha ao da configuração inicial. O professor deve fazer declarações de tipo, título, descrição e objetivos da fase, além de definir nas configurações se as atividades poderão ser executadas em série ou em paralelo, além dos prazos de início e final da fase.

A configuração de notas é que difere um pouco da configuração da lição como um todo. Agora o professor deve especificar se haverá avaliação na fase e, havendo, determina que será alcançada por ela (em pontos que variam de zero a cem), especificando o tipo global de notas para a lição (numérica ou rubrica) e a sua distribuição entre avaliação do professor, dos pares do grupo, dos pares da turma e autoavaliação, tal como mostrado no Quadro 1. 


\subsubsection{Configuração da atividade $A B P$}

A configuração de uma atividade é quase igual ao da fase, inclusive nas notas da atividade. Porém, é na página de configuração da atividade que aparecem listados os recursos, ferramentas e artefatos já existentes na lição ABP para permitir que o professor relacione-os com a atividade em configuração, como foi mostrado nas Figuras 2 e 3. Se ainda não há nada montado na lição, esse vínculo com a atividade pode ser feito depois, seja editando posteriormente a configuração da atividade ou no momento da configuração inicial, quando se cria um novo recurso, ferramenta ou artefato.

\subsubsection{Esquema de distribuição de notas}

Uma das atribuições mais complicadas de se entender do plug-in é o gerenciamento de notas das atividades ABP, pois a autoavaliação, avaliação pelos pares do grupo, pelos pares da turma e pelo professor podem ser segmentadas em cada fase e/ou atividade da lição ABP.

Para ficar clara essa distribuição, a Figura 4 apresenta um exemplo de distribuição das notas de avaliação ao longo de fases e atividades de uma lição ABP, esboçando a lógica utilizada pelo plug-in avaliado. Note que as atividades ao longo da lição apresentam diversas formatações e pesos diferentes. A Atividade 11, por exemplo, é avaliada apenas com base na nota dada pelos colegas do grupo do aluno, enquanto a Atividade 31 tem sua nota composta pela avaliação do professor, dos colegas de turma, dos colegas de grupo e do próprio aluno.

Apesar de essa composição de notas já ser suficiente para satisfazer os critérios de avaliação de Woods (2006), com base no uso dos recursos do MOODLE, o desenvolvedor do plug-in também inseriu funcionalidade de notas no nível de fase, permitindo que todos os protagonistas de avaliação pudessem dar notas ao aluno pelo conjunto de sua obra na respectiva fase. Essa faceta do plug-in, aliás, foi considerada um erro de projeto de interface do usuário, já que coloca em níveis hierárquicos diferentes (fase e atividade) funções cujas entradas de dados serão computadas como se fossem originárias do mesmo nível hierárquico, aumentando o número de passos de navegação e aumentando a complexidade da configuração da avaliação como um todo. Isso ainda pode indicar uma falta de conhecimento mais profundo sobre as funcionalidades do MOODLE, já que qualquer que seja a finalidade de se dar uma nota a nível de fase, poderia ser feita com o uso da função Tarefa do MOODLE, que em termos de interface do usuário seria mais atividade a compor a nota da fase a que pertence. 


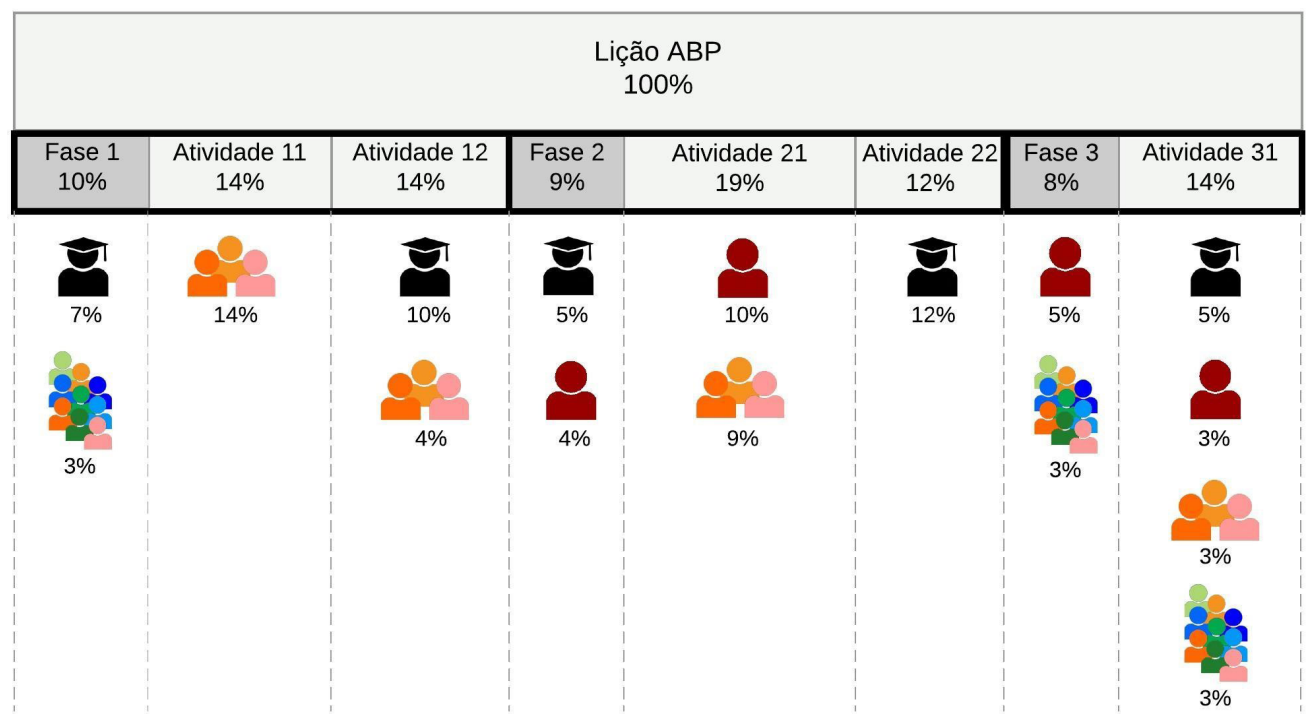

Figura 4: Exemplo de distribuição de pesos de notas com o uso do plug-in ePBL. Legenda:

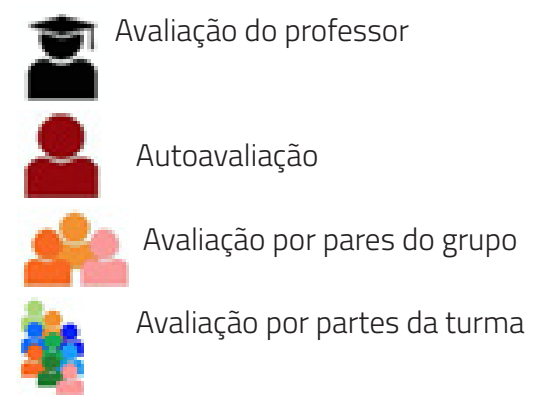

Fonte: autores (2018).

É importante perceber que cada coluna da Figura 4 representa uma página de configuração diferente para a nota da fase ou atividade. Também cada protagonista de avaliação acionado para cada coluna da Figura 4 representa um menu HTML para escolha da nota numa escala de 0 a 100 . E, apesar de essas configurações estarem distribuídas em menus distintos, posicionados em páginas variadas, o total dos pesos de notas atribuída a cada protagonista em cada fase ou atividade deve ser igual à nota total configurada para a lição como um todo, como indicada na Figura 2 e comentada na seção 3.1.2.1.

Como pode ser percebido, a avaliação da qualidade da interface do usuário do plug-in não é uma tarefa trivial. Primeiro porque é necessário entender o pro- 
cesso educacional para o qual o framework se dedica. Acrescenta-se a isso o fato de a avaliação ser focada em um plug-in, que por sua vez está envolvo pela interface do usuário do MOODLE, o que demanda uma separação, durante a avaliação, do processo interativo do plug-in do restante da interface, que faz parte do MOODLE. Apenas após ter o entendimento do processo ABP e distinguir a interface do MOODLE e do plug-in, é possível avaliar a usabilidade da interface do usuário do framework. E para tanto foi escolhida a metodologia de avaliação de usabilidade da interface do usuário baseada nas heurísticas de Nielsen (NIELSEN, 1994), apresentadas a seguir.

\section{HEURÍSTICAS DE NIELSEN}

Usabilidade está altamente relacionada a satisfação e eficiência do usuário a usar um produto. $\mathrm{O}$ seu estudo tem como objetivo elaborar interfaces capazes de permitir uma fácil interação, agradável, com eficácia e eficiência, e deve capacitar a criação de interfaces transparentes de maneira a não dificultar o processo, permitindo ao usuário pleno controle do ambiente sem se tornar um obstáculo durante a interação (GOULD; LEWIS, 1985). Para Nielsen e Molich (1990), usabilidade é tradicionalmente associada a estes cinco atributos:

Intuitividade: o sistema deve ser fácil de usar, de modo que um novo usuário consiga ter uma produtividade satisfatória.

Eficiência: o sistema deve ser eficiente de se utilizar, de modo que uma vez que o usuário tenha aprendido sobre ele, um alto nível de produtividade seja possível.

Memorização: as interfaces do sistema devem apresentar facilidade de memorização permitindo que usuários ocasionais consigam utilizá-lo mesmo depois de um longo intervalo de tempo.

Erros: o sistema deve ter uma baixa taxa de erros, caso ocorra algum, deve fornecer fácil recuperação a partir deles. Além disso, erros catastróficos não devem ocorrer.

Satisfação: o sistema deve satisfazer o usuário, seja ele iniciante ou avançado, permitindo uma interação agradável.

\subsection{AVALIAÇÃO DE INTERFACES DO USUÁRIO BASEADA NAS DEZ HEURÍSTI- CAS DE NIELSEN}

Avaliações de usabilidade possibilitam detectar e corrigir problemas de usabilidade específicos, a fim de melhorar a interação dos usuários (NIELSEN; MOLICH, 1990). Para Freire, Arezes e Campos (2012), a avaliação de usabilidade é pertinente para encontrar e analisar problemas relativos a compatibilidade, consis- 
tência, feedback e gestão de erros do sistema, assim como a satisfação do usuário. Os principais problemas encontrados ao se realizar um método ou técnica de avaliação, segundo Freire, Arezes e Campos (2012), são os seguintes:

Problemas de Interface: problema relativo à linguagem visual utilizada em um sistema, como escolha de linguagem ou imagens inadequadas, ou qualquer outro fator visual que gera uma sobrecarga cognitiva no usuário.

Problemas de Navegação: referente à localização e navegação do usuário dentro do sistema, por exemplo, forçar o usuário a fazer caminhos desnecessários de navegação.

Problemas de Conteúdo: este problema é sobre como o conteúdo e as informações são apresentadas ao usuário, páginas e textos mal diagramados, por exemplo, podem geram confusão e dificuldade na transferência de conhecimento.

Problemas de Interação: comunicação usuário e sistemas. A falha de troca entre os dois impossibilita o alcance de objetivos.

Diretrizes de usabilidade têm tipicamente milhares de regras a seguir e, portanto, muitas vezes são vistas como intimidantes pelos desenvolvedores. Para simplificar o uso dos princípios de usabilidade durante o design de um sistema, Nielsen e Molich (1990) propuseram um conjunto de dez heurísticas gerais de usabilidade que são amplamente utilizadas nesse tipo de avaliação. Para Nielsen e Molich (1990) o objetivo da avaliação heurística é encontrar os problemas de utilização na concepção, de modo que eles possam ser atendidos como parte de um processo iterativo de design.

Heurísticas são regras gerais que descrevem uma propriedade comum, neste caso, derivadas de conhecimento de aspectos psicológicos, computacionais e sociológicos dos domínios do problema. São independentes de uma tecnologia específica e resultantes de uma base de problemas comuns entre muitos sistemas (NIELSEN; MOLICH, 1990). As dez Heurísticas de Usabilidade, por Nielsen e Molich (1990), são:

1. Visibilidade do status do sistema: o sistema deve sempre manter os usuários informados sobre o que está acontecendo, através de aviso apropriado e em tempo razoável.

2. Correspondência entre o sistema e o mundo real: o sistema deve falar a linguagem dos usuários, com palavras, frases e conceitos familiares a ele, em vez de termos orientados ao sistema, e preferencialmente no idioma nativo desse usuário. Deve seguir convenções do mundo real, mostrando as informações que aparecem em uma ordem natural e lógica.

3. Controle do usuário e liberdade: usuários frequentemente escolhem algumas funções do sistema por engano e vão precisar sempre de uma "saída de emergência" claramente marcada para sair daquele estado indesejado, sem ter que 
passar por um extenso “diálogo”. Deve fornecer suporte para desfazer e refazer ações.

4. Consistência e padrões: os usuários não precisam adivinhar que diferentes palavras, situações ou ações significam a mesma coisa. Siga os padrões da plataforma, padrões de interface, tanto em forma, como em cores e posições.

5. Prevenção de erros: ainda melhor do que boas mensagens de erro é um projeto cuidadoso que impede que em primeiro lugar esse erro possa ocorrer. Eliminar as condições passíveis de erros e verificá-las, apresentado aos usuários uma opção de confirmação antes de se comprometerem com uma determinada ação.

6. Reconhecimento em vez de recordação: minimizar a carga de memória do usuário tornando objetos, ações e opções visíveis. O usuário não deve ter de se lembrar da informação de uma parte do diálogo para outra. Funcionalidades e opções do sistemas devem estar visíveis e serem facilmente acessadas.

7. Flexibilidade e eficiência de utilização: aceleradores - invisíveis para o usuário novato - podem frequentemente acelerar a interação para o usuário experiente. O sistema pode atender a ambos os usuários, inexperientes e experientes, e permitir-lhes personalizarem ações frequentes.

8. Estética e design minimalista: os diálogos não devem conter informações irrelevantes ou raramente necessárias. Cada unidade extra de informação em um diálogo compete com as unidades relevantes de informação e diminui sua visibilidade relativa.

9. Ajude os usuários a reconhecer, diagnosticar e resolver erros: mensagens de erros devem ser expressas em linguagem clara (sem códigos), indicar com precisão o problema e construtivamente sugerir uma solução.

10. Ajuda e documentação: mesmo que seja melhor que um sistema possa ser usado sem documentação, pode ser necessário fornecer uma ajudae documentação. Qualquer informação deve ser fácil de ser pesquisada com foco na atividade do usuário, deve fornecer uma lista de passos concretos a serem seguidos e não ser muito grande.

\subsection{AVALIAÇÃO HEURÍSTICA EM GRUPO}

Avaliação heurística pode apresentar certos desafios se realizada por um único avaliador, visto que este pode não ser capaz de identificar todos os problemas de usabilidade de uma interface. Nielsen (1994) afirma que avaliadores diferentes podem encontrar problemas diferentes, com isso, envolver múltiplos avaliadores em uma avaliação heurística pode melhorar a eficácia da metodologia. Certamente alguns erros são mais evidentes e perceptíveis a quase qualquer avaliador, outros exigem maior esforço para serem encontrados, e nem todos avaliadores são capazes de percebê-los. Nielsen (1994) ainda afirma que nunca um avaliador será o 
melhor avaliador em todos os casos e com isso recomenda de três a cinco avaliadores por pesquisa, visto que um maior número de avaliadores não representa necessariamente uma maior quantidade de informações e erros descobertos.

A avaliação deve ser feita individualmente por cada avaliador, em sessões de no máximo duas horas. Os avaliadores devem fazer os relatórios individuais, gravando em áudio suas percepções, ou preferencialmente, de forma escrita. Somente após o término de suas avaliações, os avaliadores podem se comunicar e comparar os relatórios, garantindo assim uma avaliação imparcial (NIELSEN, 1994).

\section{METODOLOGIA DE AVALIAÇÃO DO PLUG-IN EPBL}

A metodologia utilizada neste estudo é de natureza interpretativista, pois se baseia na interpretação da observação do uso dos recursos de interação entre o plug-in e o usuário, através da interface que o software oferece ao se realizar procedimentos comumente esperados para rotina de uso da tecnologia. Para tanto, a metodologia utilizada é a da avaliação de interface do usuário baseada nas heurísticas de Nielsen, explicadas na seção anterior.

Em termos de instrumentalização, foi necessário apenas ter uma instalação do MOODLE equipada com o plug-in acessível a três avaliadores experientes nas heurísticas de Nielsen, que usaram um formulário para realizar as anotações pertinentes de modo padronizado. Assim, os avaliadores poderiam acessar o MOODLE e fazer uso dos recursos oferecidos pelo plug-in de acordo com parâmetros preestabelecidos.

Como avaliadores, foram convidados três profissionais experientes na área de Experiência do Usuário, incluindo avaliação de usabilidade pelas heurísticas de Nielsen. Porém, os avaliadores não tinham conhecimento sobre a metodologia ABP, tampouco o contexto de uso do framework especificamente. Por isso, receberam dezessete vídeos explicativos, totalizando uma hora de quinze minutos de apresentação sobre a metodologia $\mathrm{ABP}$, sobre os conceitos de $\mathrm{ABP}$ em rede e principalmente sobre como usar o plug-in. Dessa forma, buscou-se equalizar o conhecimento dos avaliadores no que diz respeito ao paradigma pelo qual o plug-in foi desenvolvido, como também ao próprio uso da tecnologia.

\subsection{ROTEIRO DE USO DO PLUG-IN PARA AVALIAÇÃO DA USABIILIDADE}

Junto com as instruções de uso, os avaliadores receberam a estrutura de lição $\mathrm{ABP}$ que deveriam montar para realizar os procedimentos mais básicos e frequentes na utilização do plug-in por um professor. A estrutura de lição ABP é apresentada a seguir, em forma de lista não numerada. Os elementos descritos na estrutura fazem parte de uma lição ABP, de acordo com a terminologia utilizada no plug-in. Os diferentes níveis de tabulação representam a hierarquia desses elemen- 
tos, e as datas são informações importantes no processo de configuração da lição ABP através do plug-in. Tudo isso fartamente explicado nos vídeos instrucionais.

Lição ABP (31/08 a 02/10)

Recurso inicial 01 (arquivo PDF).

Recurso inicial 02 (livro).

Fase 1 (31/08 a 18/09) com atividades concorrentes - Peso: 20\% (Escala numérica).

(Distribuição: 20\% do professor).

Atividade A (31/08 a 18/09) - Peso: 10\% (Escala numérica).

(Distribuição: 5\% do professor; 5\% do grupo).

Recurso 11 (arquivo PDF).

Recurso 12 (página HTML).

Ferramenta 11 (chat).

Artefato 11 (wiki).

Atividade B (10/09 a 18/09) - Peso: 20\% do total (Escala numérica).

(Distribuição: $15 \%$ do professor; $5 \%$ da turma).

Recurso 13 (livro).

Artefato 12 (tarefa).

Fase 2 (19/09 a 02/10) - Peso: 50\% do total (Rubrica).

(Distribuição: $40 \%$ do professor; $10 \%$ da autoavaliação).

Atividade C (19/09 a 02/10).

Recurso 21 (arquivo PDF).

Recurso 22 (página HTML).

Ferramenta 21 (fórum).

Ferramenta 22 (chat).

Artefato 21 (tarefa).

Rubrica:

Objetivo 1: Proatividade.

Critérios: Pouco (20\%); Médio (60\%); Muito (100\%).

Objetivo 2: Liderança.

Critérios: Seguidor (0\%); Vice-líder (50\%); Líder (100\%).

Feita a configuração da lição ABP, então foi solicitado que o avaliador mudasse a configuração da Fase 1 de modo que ela não mais aceitasse atividades 
concorrentes. A Atividade A deveria encerrar quando a Atividade B iniciasse. O objetivo era fazer com que o avaliador não apenas experimentasse o uso do plug-in para montar uma lição ABP, mas também pudesse alterar algum parâmetro da lição através do plug-in após a lição ser totalmente configurada.

\subsection{MARCADORES DE VIOLAÇÕES DAS HEURÍSTICAS DE NIELSEN}

Ao final, os relatórios das três avaliações foram reunidos, comparados e unificados para compor um diagnóstico consolidado sobre a interface do usuário do plug-in ePBL de acordo com as heurísticas de Nielsen. O relatório é baseado no mapa de navegação do plug-in, apresentado na Figura 5, entregue aos avaliadores apenas na fase de consolidação das suas respectivas avaliações. Já navegabilidade é um dos fatores a serem considerados na avaliação e que, portanto, não poderia contar com um mapa para nortear a navegação de antemão.

Para dar produtividade ao processo de documentação da avaliação, foi fornecido o mapa de navegação semelhante ao apresentado na Figura 5, porém, com cada caixa referente a uma tela do plug-in contendo marcadores correspondentes a cada uma das dez heurísticas de Nielsen. Foi solicitado que, para cada heurística, o avaliador percorresse a interface do plug-in e marcasse as heurísticas de Nielsen violadas em cada tela. Ao mesmo tempo, o avaliador também deveria fazer anotações referentes a cada marcação feita. Ao final, as marcações e anotações dos três avaliadores foram coletados e suas respostas consolidadas, como apresentado na próxima seção. 


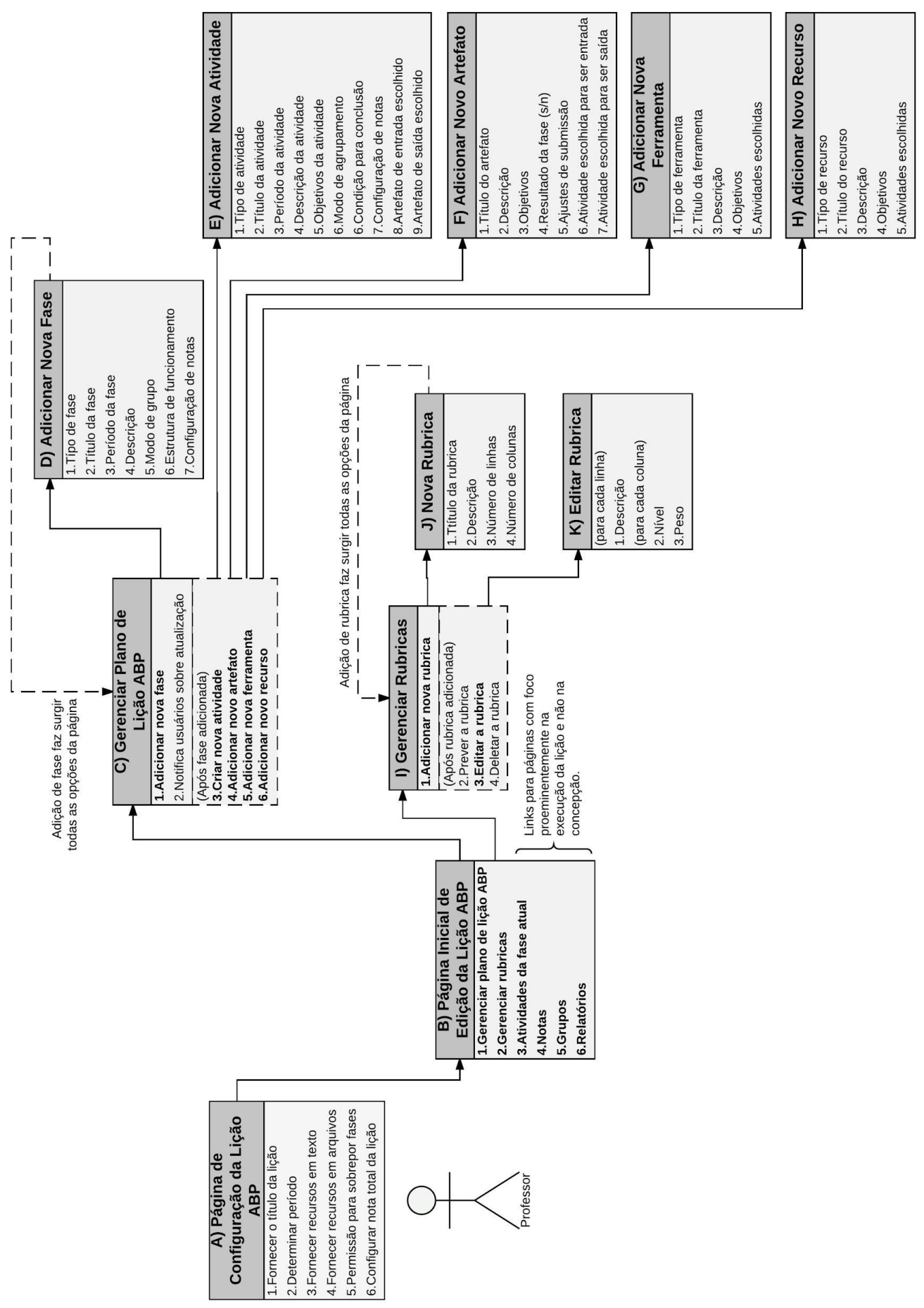

Figura 5: Diagrama de caso de uso com a estrutura de navegação do plug-in ePBL. Fonte: autores (2018). 


\section{RESULTADOS DA AVALIAÇÃO HEURÍSTICA EM GRUPO}

O mapa de avaliação consolidado, com as marcações dos três avaliadores, é apresentado na Figura 6.

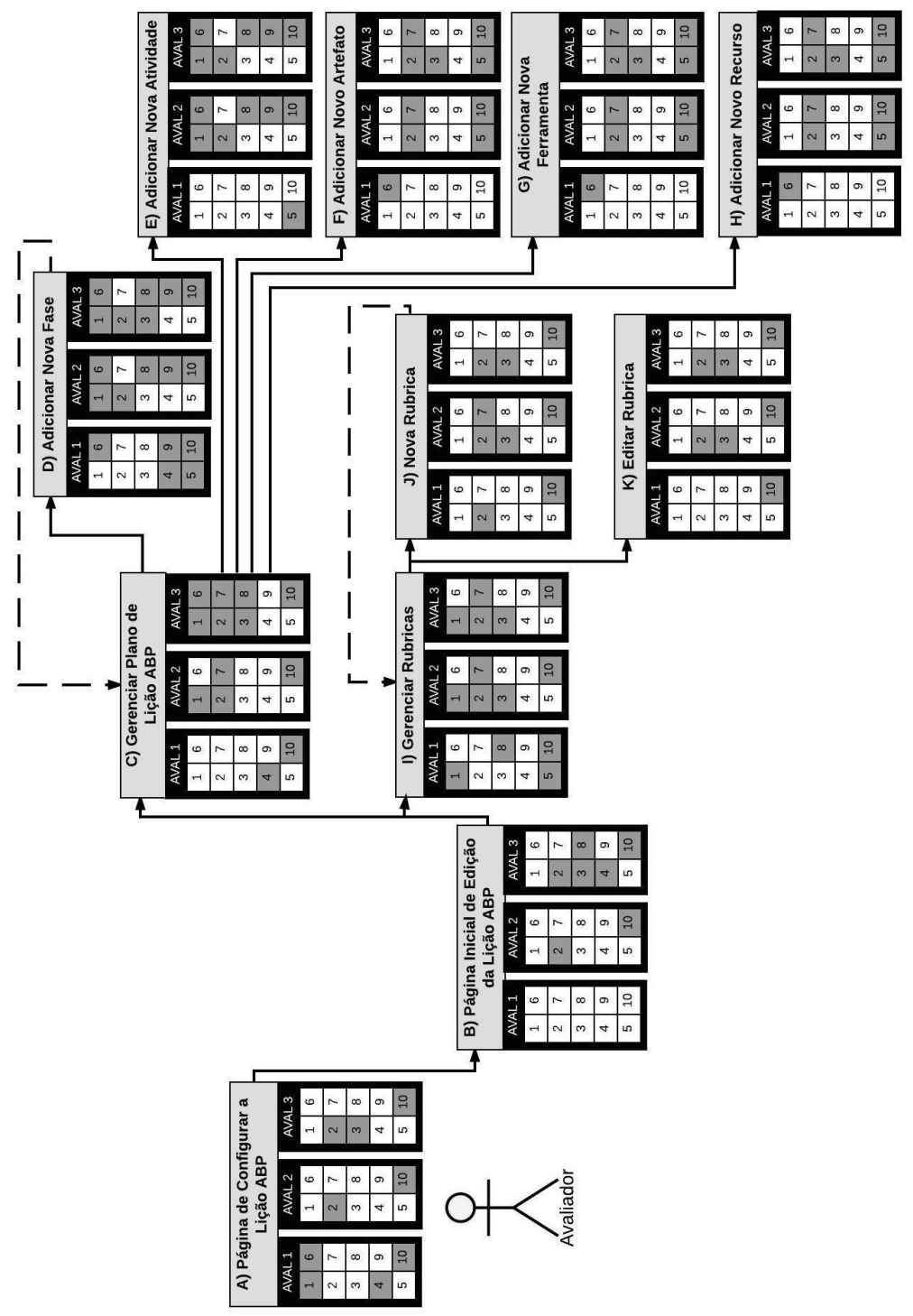

Figura 6: Mapa consolidado de avaliação heurística do plug-in ePBL. Fonte: Autores (2018).

Esse mapa serve para mostrar as diferenças do resultado das percepções dos três avaliadores, ao mesmo tempo em que revela os problemas mais claramente 
identificados na interface do plug-in, segundo as heurísticas de Nielsen. Note que o fato de haver algumas discrepâncias entre as marcações dos diferentes avaliadores não é um problema. O uso de avaliação da metodologia de avaliação utilizada serve justamente para dar ao processo diferentes interpretações sobre quais heurísticas de Nielsen foram violadas. Eventuais citações de violações não fundamentadas podem ser explicadas e desconsideradas pelo desenvolvedor, sem prejuízo para o resto da avaliação.

\subsection{CONSOLIDAÇÃO DAS ANOTAÇÕES DOS AVALIADORES}

A seguir, segue a lista de heurísticas de Nielsen, com a consolidação das anotações dos diferentes avaliadores ${ }^{1}$ sobre violações de cada uma delas na concepção da interface do usuário do plug-in avaliado.

1) Visibilidade do status do sistema:

a) Ao adicionar nova fase ou atividade (páginas D e E), a configuração de notas é desafiadora para o usuário, especialmente quando se edita uma fase ou atividade já existente, sendo facilitado o erro referente à totalização de notas da lição, que tem de ser controlada manualmente pelo usuário, ao não coincidir soma de pontos das fases e atividades com o total especificado na configuração da lição.

b) No gerenciador de plano da lição, nada existe para indicar que artefatos, ferramentas e recursos se relacionam com qual atividade. Para descobrir o que se relaciona com que, o usuário precisa entrar no modo de edição de tais funções para descobrir (página $\mathrm{C}$ ).

c) O mesmo ocorre para os períodos de disponibilidade das atividades para os alunos (página $\mathrm{C}$ ).

d) $\mathrm{O}$ problema semelhante se repete quanto às rubricas no gerenciador de rubricas. O usuário tem de entrar no modo de edição de uma rubrica para saber que parâmetros e pesos foram configurados (página I).

e) Na página inicial da lição (página C), não é possível saber quais atividades estão ativas ou não durante o uso. Isso só é possível em relação às fases.

2) Correspondência entre o sistema e o mundo real:

a) Os materiais de ajuda ou estão em inglês ou inexistem, apesar de haver o ícone correspondente na interface em todas as páginas do plug-in.

b) A forma como se monta a lição no sistema não corresponde ao que ocorre

1 As anotações vêm desacompanhadas de capturas de telas pelo fato de o desenvolvedor do plug-in não ter autorizado expressamente o uso de seu software para publicação deste texto. 
no mundo real no gerenciador de plano de lição (página C). As complicadas configurações de notas e pesos para os protagonistas de avaliação nas fases e atividades é fator impeditivo para um processo dinâmico e flexível de montagem da lição, causando a necessidade de se ter um plano rígido, já pronto, anotado em papel, para se configurar a lição.

c) A necessidade de configuração de horas e minutos, sendo obrigatória, não parece corresponder ao mundo real, já que as atividades ABP, em geral, duram semanas, e tem seus prazos estabelecidos em dias (páginas B, D e E). Apresentar desnecessariamente horas e minutos apenas aumenta a carga de trabalho do usuário, as suas chances de erro e a poluição visual na sua interface.

d) Ao se criar uma nova rubrica (página J), o sistema utiliza os termos "linha" e "coluna", em vez de "critério" e "conceito", que são utilizados no mundo real.

3) Controle do usuário e liberdade:

a) Se o usuário quiser editar uma rubrica, após a ter configurado inicialmente, não pode plenamente (página I). Só é autorizada a alteração dos critérios e pesos, mas não é permitida a alteração do número de critérios nem de faixas. Havendo necessidade de fazer tal alteração, o usuário é obrigado a criar outra rubrica e, caso tenha usado a primeira em atividades e fases, também tem de fazer a substituição.

b) O link com o nome da lição, no rodapé de todas as páginas, leva o usuário até a página inicial da sala do MOODLE onde o módulo do plug-in foi instanciado, e não até a página principal interna do plug-in, como seria normalmente entendido.

c) Na página do gerenciador do plano de lição (página C), ao se clicar em um recurso (não nas suas configurações) já criado dentro do plano de gerenciamento, é possível fazer algumas alterações de suas configurações. Porém, caso o usuário queira cancelar a alteração, ele é direcionado à página inicial do curso, e não de volta ao estado anterior, tela de gerenciamento de plano ABP, não apresentando uma forma clara de como o usuário pode desistir de fazer a edição do recurso.

4) Consistência e padrões:

a) Na página de configuração da lição (página B), uma escala maior que varia de 0 a $200 \%$ é inconsistente com a escala de $0-100 \%$ utilizada em todas as outras páginas do plug-in em que notas são configuradas.

b) Na página de edição da configuração da lição (página B), caso um recurso inicial seja um arquivo ou livro, ele não pode ser adicionado pelo campo "Recurso", arrastando o arquivo ou adicionando por um menu, tal como ocorre em "Arquivos do Problema", violando a heurística de Consistência e Padrões, pois não possui uma denominação correspondente a recurso. 
c) O problema citado no item $4 \mathrm{~b}$ se repete nas páginas de adição de nova fase, novo artefato, nova ferramenta e novo recurso (páginas D, F, G e H).

d) No gerenciador do plano de lição (página C), ao se acessar um Chat já instanciado, não há um botão para reverter o acesso, sendo o usuário obrigado ou a usar o botão de Voltar do navegador ou usar o menu superior geral de navegação do MOODLE.

5) Prevenção de erros:

a) O estabelecimento de relações dos artefatos, ferramentas e recursos com as atividades é altamente propenso a erros (páginas $\mathrm{C}$ e decorrentes). $\mathrm{O}$ usuário se sente pressionado a ter um mapa em papel para não se perder com as configurações necessárias.

b) O usuário não é avisado que, ao criar uma nova rubrica, recurso ou artefato (páginas J, F e H), ele não terá terminado o processo, apenas instanciou a função que precisa de configuração adicional em um segundo momento. $\mathrm{O}$ instanciamento de um recurso URL, por exemplo, cria uma instância URL do MOODLE cujo endereço é padrão e igual a 1 (número um) e que precisa, após criado o recurso, ser substituído por um endereço web, com início "http://www." mais o dado que complementa tal endereço.

c) O gerenciamento de notas é altamente propenso a erros nas páginas de Fase e Atividades (páginas D e E), pois exige alta carga de memorização do usuário na configuração dos pesos das notas, para que a sua totalização dentre as atividades e fases seja igual à nota total configurada para o plug-in.

d) Nas páginas de criação de fases e atividades (páginas D e E), o usuário tem menus com notas em escala de 0 a 100, mesmo que a nota total da atividade ou fase não permita o uso de toda essa escala, sendo isso uma agente gerador de erros nas configurações de notas.

6) Reconhecimento em vez de recordação:

a) Na criação de nova fase e nova atividade, os campos Tipo de Fase e Tipo de Atividade (páginas D e E) denotam termos que requerem carga de recordação do usuário, sem necessidade. Aliás, não foi encontrado impacto algum em termos de funcionalidade útil na configuração dessas variáveis.

b) Os ícones referentes a abrir/fechar fase confundem o usuário nas páginas principais do plug-in (páginas A e C), pois usam as mesmas cores que definem o status de fase aberta e fechada para o aluno.

c) Em várias páginas do plug-in (páginas $\mathrm{A}, \mathrm{D}, \mathrm{F}, \mathrm{G}$ e H), nenhum dos nomes das opções disponíveis para a inserção de um novo recurso faz referência a essa ação.

7) Flexibilidade e eficiência de utilização:

a) A criação de nova rubrica, artefato e recurso (páginas J, F e H) se dá em 
dois tempos, como citado no item $5 \mathrm{~b}$, prejudicando em muito a produtividade na criação de elementos que compõem a lição ABP.

b) Um usuário experiente não tem como agilizar a criação de fases/atividades com duplicação do que já está feito na página de gerenciamento da lição para posterior diferenciação do original recém copiado (página C).

c) O mesmo ocorre no gerenciador de rubrica (página I). Para criar uma rubrica semelhante, não há como partir de uma já criada. O processo tem de começar do início.

8) Estética e design minimalista:

a) Na criação de nova fase e nova atividade, os campos Tipo de Fase e Tipo de Atividade (páginas D e E) denotam termos que requerem carga de recordação do usuário, sem necessidade (vide item $6 \mathrm{c}$ ).

b) As abas Grupos e Gerenciador de Rubrica (páginas A e C) deveriam ser posicionados na caixa Administração, já que são funções usadas pontualmente e apenas no processo de criação da lição ABP.

c) O gerenciador de rubricas (página I) apresenta desnecessariamente uma rubrica vazia, sem nenhuma informação, antes de ela ser devidamente configurada.

9) Ajude os usuários a reconhecer, diagnosticar e resolver erros:

a) A configuração de prazos em Nova Fase e Nova Atividade (páginas D e E) não ajuda o usuário a perceber violação de prazos. Não há informação de como está o calendário montado até então, o que faz que o usuário descubra se cometeu algum lapso na configuração da fase ou atividade apenas quando tentar salvar a configuração.

b) Ao adicionar novo recurso (página $\mathrm{H}$ ), quando o usuário tenta enviar um arquivo que não é compatível com o recurso, o sistema somente notifica que o arquivo é invalido, e não apresenta o tipo esperado de arquivo.

10) Ajuda e documentação:

a) Todas as páginas têm falta ou problemas com o recurso Ajuda. Documentação é inexistente, seja embarcada com o software ou posicionada na web.

b) O link Documentação de MOODLE não deveria ser alocado no rodapé de todas as páginas do plug-in, pois se estamos configurando esse software, posicionar um link para uma documentação que não vai ajudar na montagem da lição, além de ser inútil, pode atrapalhar o usuário e criar a expectativa de que ele encontrará alguma documentação útil sobre o plug-in através daquele link.

c) Ao adicionar nova fase (página D) com violação das regras estabelecidas para existência de fases sequenciais ou paralelas, não há a apresentação de qualquer ajuda para o usuário entender seu erro. 
d) Nas páginas referentes a rubricas (páginas I, J e K), apesar de fazer uso de terminologia especializada, não há qualquer recurso de ajuda para o usuário iniciante ou leigo.

e) As páginas iniciais do plug-in (páginas A, B e C) não apresentam qualquer texto introdutório ou link para mais explicações sobre como montar uma lição ABP com tal tecnologia.

\subsection{ANÁLISES ADICIONAIS}

A partir da avaliação das heurísticas de Nielsen, foram feitas análises adicionais no código do plug-in para verificar sua adequação aos padrões aceitáveis de boas práticas de desenvolvimento de código, como documentação interna ao código, checar a sua compatibilidade com os padrões de desenvolvimento de plug-ins recomendados pelo MOODLE e entender algumas configurações que não foram compreendidas, pela falta total de documentação de uso fornecido pelo desenvolvedor.

O plug-in ePBL se mostra incompleto em alguns aspectos, como o de não ter documentação de ajuda pronta e em idioma português. Ao investigar a origem desse problema, foi notado que o arquivo de idioma estava totalmente traduzido para português. Ainda assimDesta forma, surgir termos em inglês na interface do usuário foi um indicativo havia elementos da interface do usuário cujos termos não estavam listados no arquivo de idioma, mas sim no próprio código do plug-in. Isso é um problema para localizar a interface do usuário para outros idiomas. Isso implica que o desenvolvimento do mesmo não estava de acordo com as diretrizes de desenvolvimento de plug-ins do MOODLE (MOODLE, 2016b).

Ao ser submetido a um teste de funcionalidade em que todos os seus recursos foram ativados para verificação de pleno funcionamento, em pelo menos uma das funções, houve erro ao gerar uma página em branco, quando se deveria acessar uma instância wiki do MOODLE. Esse foi mais um elemento para reforçar a conclusão de que se trata de um software inacabado.

Também foi percebido que o código do plug-in tinha pobre documentação, o que dificultou a compreensão de algumas de suas funções. Porém, o que mais chamou a atenção foi que elementos da interface do usuário simplesmente não tinham função efetiva, o que indicava que estavam no código para um futuro uso, mas não na versão que foi entregue para a UFSC.

\section{CONSIDERAÇÕES FINAIS}

Esse trabalho teve como objetivo original avaliar a viabilidade do uso do plug-in ePBL para o MOODLE, a fim de ser utilizado em processos de trabalho e 
ensino na Universidade Federal de Santa Catarina. Pelos resultados obtidos na avaliação heurística da interface do usuário do plug-in, realizado por três profissionais da área de Experiência do Usuário, a conclusão é que a UFSC não deve usar o plug-in em seus processos de trabalho, tampouco de ensino.

O plug-in apresenta uma interface de usuário em um nível muito primitivo de usabilidade, apresentando problemas elementares quanto às heurísticas de Nielsen, sendo bastante contraprodutivo seu uso para fins educacionais. Não há documentação nem recursos de ajuda, sejam internos ao software, sejam disponibilizados na web. A interface do usuário não é totalmente localizável para o idioma português sem alteração do código principal do software.

A avaliação limitou-se ao processo de montagem de uma lição ABP simples, não tendo sido feita análise do processo de aplicação da lição, que envolve a disponibilidade de esta ser usada pelos alunos. Isso foi motivado pelo fato de que o resultado da avaliação do processo de montagem da lição $\mathrm{ABP}$ apresentou resultados contundentes o suficiente para se chegar à essa conclusão.

O único uso educacional recomendado para o plug-in é no contexto de ensino na área de Experiência do Usuário, podendo-se usar o software em estudo de caso para demonstrar o que não deve ser feito em termos de usabilidade de interface do usuário.

\section{REFERÊNCIAS}

ALBANESE, M.; MITCHEL, S. Problem-based learning: a review of literature on its outcomes and implementation issues. Academic Medicine, 68, 1993. p. 52-81.

AL-DOUS, K. K.; SAMAKA, M. The design and delivery of hybrid ABP sessions in MOODLE. International Journal of Education and Information Technologies, v. 9, p. 105-114, 2015.

ALI, Z. F.; AL-DOUS, K.; SAMAKA, M. Problem-based learning environments in MOODLE: Implementation approches. In: IEEE GLOBAL ENGINEERING EDUCATION CONFERENCE. EDUCON. v. 2015-April. n. March 2015. p. 868-873.

ALI, Z.; SAMAKA, M.; SHABAN, K. A virtual problem based learning environment in MOODLE. In: INTERNATIONAL TECHNOLOGY, EDUCATION AND DEVELOPMENT CONFERENCE, 5.,2001. Inted2011. n. March, 2011. p. 2421-2428.

BARROWS, H. Problem-based learning in medicine and beyond: a brief overview. New Directions for Teaching and Learning, n. 68, p. 3-12, 1996. doi:10.1002/ tl.37219966804.

BELLAND, B.; GLAZEWSKI, K.; ERTMER, P. Inclusion and problem-based learning: Roles of students in a mixed-ability group. RMLE Online, v. 32, n. 1, p. 1-19, 2009.

COLLEGIAL CENTRE FOR EDUCATIONAL MATERIALS DEVELOPMENT (CCDMD). What is problem based learning? Disponível em: <http://pbl.ccdmd.qc.ca/ 
resultat.php? action=aboutApproach\&endroitRetour=7\&he=768>. Acesso em: 2 abr. 2016.

FARIAS, G.; SPANHOL, F.; SOUZA, M. Uma revisão narrativa sobre soluções para aprendizagem em rede baseada em problemas. In: M. SOUZA, M.; STEFANI, C. (Ed.). Educação fora da caixa. São Paulo: Perse, 2016a.

The use of LMS to support ABP practices: a systematic review. Journal of Research \& Method in Education (IOSR-JRME), v. 6, n. 5, p. 51-59, 2016b. ISSN: 23207388 .

FREIRE, L. L.; AREZES, P. M.; CAMPOS, J. C. A literature review about usability evaluation methods for e-learning platforms. Work-a Journal of Prevention Assessment \& Rehabilitation, v. 41, p. 1038-1044, 2012.

GOMES, A. P.; REGO, S. Transformação da educação médica: é possível formar um novo médico a partir de mudanças no método de ensino-aprendizagem? Revista Brasileira de Educação Médica, v. 354, n. 354, p. 557-566, 2011.

GOULD, J. D.; LEWIS, C. Designing for usability: key principles and what designers think. Communications of the ACM, v. 28, n. 3, 1985.

MOODLE. MOODLE plugins. Disponível em <http://www.MOODLE.org/plugins>. Acesso em: 14 ago. 2016a.

MOODLE coding guidelines. Disponível em: < https://docs.MOODLE.org/dev/ Coding >. Acesso em: 5 out. 2016b.

NEVILLE, A. Problem-based learning and medical education forty years on. Medical Principles and Practice, n. 18, v. 1, p. 1-9, 2009. doi:10.1159/000163038. PMID 19060483.

NIELSEN, J. Usability inspection methods. Nova York: John Wiley \& Sons, 1994. .; MOLICH, R. Heuristic evaluation of user interfaces. In: SIGCHI CONFERENCE ON HUMAN FACTORS IN COMPUTING SYSTEMS. Proceedings. ACM, 1990.

THOMAS, J. W. A review of research on project-based. 2000. Disponível em : <http:// www.bie.org/images/uploads/general/9d06758fd346969cb63653d00dca55c0.pdf $>$. Acesso em: 2 abr. 2016.

WALKER, A.; LEARY, H. A Problem based learning meta analysis: differences across problem types, implementation types, disciplines, and assessment levels. IJPBL, v. 3, n. 1, p. 3-24, 2009.

WOOD, D. F. Problem-based learning. 2003. Disponível em: <https://www.bmj.com/ content/32 6/7384/328>. Acesso em: 2 abr. 2016. doi.org/10.1136/bmj.326.7384.328 . Problem-based learning: how to gain the most from PBL. Hamilton: Griffin Printing Limited, 1994.

WOODS, D. R. Helping your students gain the most from ABP. In: CONFERENCIA ÁSIA-PACÍFICO SOBRE ABP, 2., 2000. Apresentação em plenária. 2000. . Preparing for ABP. Waterdown, ON, Canadá: Don Woods, 2006. 